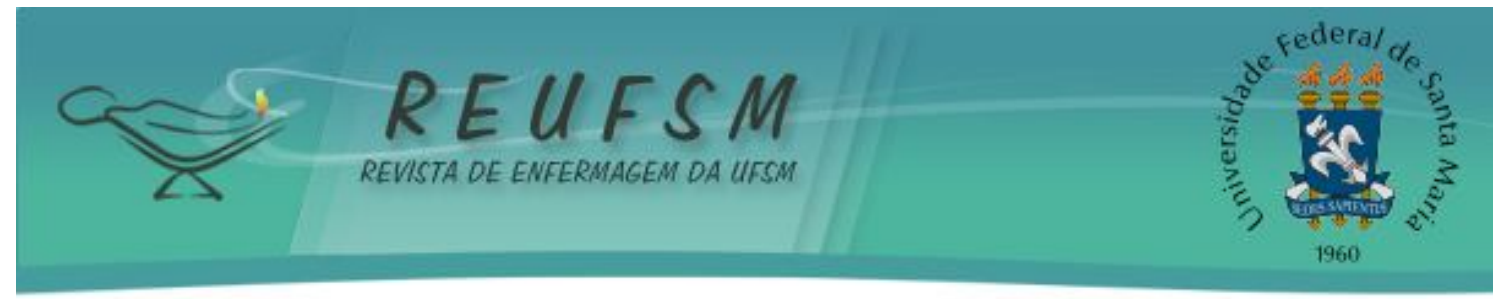

ARTIGO ORIGINAL

\title{
RELACIONAMENTO ENTRE PROFISSIONAIS DE SAÚDE E PARTURIENTES: UM ESTUDO COM DESENHOS ${ }^{1}$
}

\section{RELATIONSHIP BETWEEN HEALTH PROFESSIONALS AND PART URIENTS: A ST UDY WITH DRAWINGS}

\section{RELACIÓN ENT RE PROFESIONALES DE LA SALUD Y PART URIENT AS: UN EST UDIO CON DIBUJ OS}

\author{
Luciano Marques dos Santos ${ }^{2}$ \\ Samantha Souza da Costa Pereira ${ }^{3}$ \\ Vivane Euzébia Pereira Santos 4 \\ Rosana Castelo Branco de Santana ${ }^{5}$ \\ Monica Cecília Pimentel de Melo ${ }^{6}$
}

Resumo: Este estudo buscou analisar o relacionamento entre profissionais de saúde e parturientes no centro obstétrico de uma maternidade pública do interior da Bahia. Tratou-se de um estudo descritivo, exploratório e qualitativo, realizado com treze puérperas através de entrevistas semiestruturadas, no período de fevereiro a abril de 2010 e que respeitou a resolução 196/ 96 do Conselho Nacional de Saúde. A Análise de Conteúdo dos dados demonstrou que as entrevistadas caracterizaram a assistência recebida como indiferente, pois os profissionais de saúde estabeleceram uma relação assimétrica e de poder, sendo o contato maior com a parturiente no período expulsivo. Há necessidade da adoção de ações que visem o acolhimento da parturiente, fazendo desta uma experiência humanizada, devolvendo à mulher o protagonismo deste tão sublime momento.

Descritores: Enfermagem obstétrica; Trabalho de parto; Parto normal; Saúde da mulher; Assistência à saúde.

\begin{abstract}
This study aimed to analyze the relationship between health professionals and parturients in the obstetric center at a public maternity in the interior of Bahia. This is a qualitative descriptive exploratory study that complied with the Resolution 196/96 of the National Health Council and was made in the period from February to April 2010, through semi-structured interviews with thirteen new mothers. The content analysis showed that the assistance new mothers received was indifferent, because health professionals have established an asymmetrical and power relationship, with the largest contact with the parturient occurred during the expulsive period. It is necessary the adoption of actions aimed at the host's mother, making this experience a humanized, assigning women the main role in this sublime moment.

\footnotetext{
${ }^{1}$ Artigo elaborado a partir do Trabalho de Conclusão de Curso intitulado Percepção da puérpera sobre a atenção no processo parturitivo em uma maternidade pública do interior da Bahia e apresentado ao Colegiado de Enfermagem da Faculdade de Tecnologia e Ciências, Feira de Santana-BA, Brasil. 2010.

2 Enfermeiro. Mestre em Enfermagem. Professor Assistente da Universidade Federal do Vale do São Francisco (UNIVASF). Líder do Grupo de Estudos e Pesquisas sobre Cuidado em Saúde (GEPECS) e pesquisador do Núcleo de Estudos sobre Gênero e Atenção à Saúde da Mulher/ NUGAM. E-mail: Iuciano.marques@univasf.edu.br.

3 Enfermeira. Especialista em Saúde Pública. Hospital Ortopédico, Feira de Santana-Bahia. E-mail: samcosta01@yahoo.com.br

${ }^{4}$ Enfermeira. Doutora em Enfermagem. Professora Adjunta da UNIVASF. Pesquisadora do gepecs e nugam. E-mail: vivianeepsantos@gmail.com

5 Estudante. Curso de Graduação em Enfermagem da universidade Estadual de Feira de Santana. E-mail: rosanacastelo@hotmail.com

6 Enfermeira. Mestre em Enfermagem. Professora Assistente da UNIVASF. Líder do NUGAM. E-mail: monquinamelo@gmail.com
} 


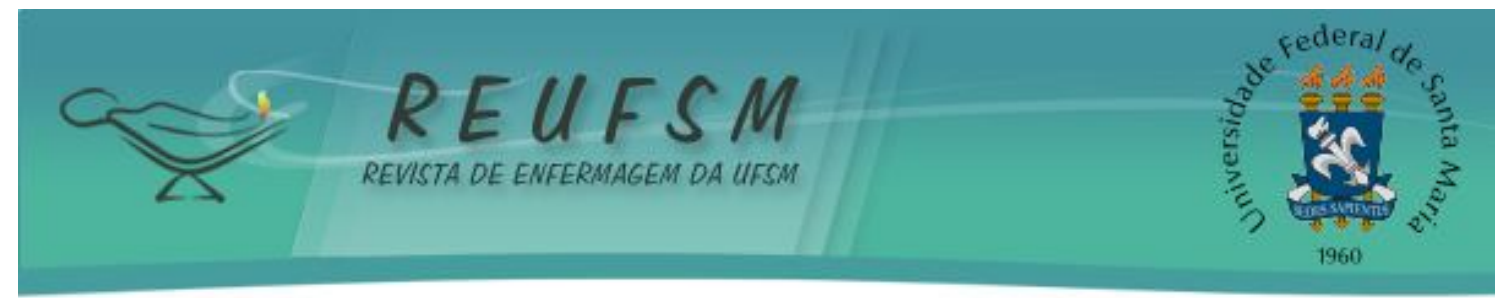

Descriptors: Obstetrical nursing; Labor obstetric; Natural childbirth; Women's health; Delivery of heal th care.

Resumen: Este estudio buscó analizar la relación entre profesionales de la salud y parturientas en un centro obstétrico de una maternidad pública del interior del estado de Bahia. Fue un estudio descriptivo, exploratorio y cualitativo, según la resolución 196/96 del Consejo Nacional de Salud, en el periodo de febrero a abril de 2010, que se llevó a cabo por medio de entrevistas semiestructuradas con trece puérperas. El Análisis de Contenido de los datos demostró que las entrevistadas reflejaron la asistencia recibida como indiferente, pues los profesionales de la salud establecieron una relación asimétrica y de poder, siendo que el mayor contacto con la parturienta fue en el periodo del alumbramiento. Existe una gran necesidad de establecer acciones dirigidas a un acompañamiento más directo de la parturienta, para que el parto se convierta en una experiencia más humana, que le devuelva el rol protagónico de tan sublime momento.

Descriptores: Enfermería obstétrica; Trabajo de parto; Parto normal; Salud de la mujer; Atención a la salud.

\section{INTRODUÇÃO}

Historicamente, o parto ocorria no contexto domiciliar, e a responsabilidade de conduzi-lo era privativamente feminina, sendo realizado pelas parteiras, curandeiras e comadres que, embora não dominassem o saber científico, eram respeitadas pela experiência que tinham no ofício de partejar. As parteiras promoviam conforto à parturiente, oferecendo-Ihe alimentos, bebidas e encorajando-as com palavras agradáveis. Desta forma, as mulheres preferiam a companhia das parteiras por razões humanitárias, psicológicas e devido ao tabu de mostrar os genitais. ${ }^{1}$

As mudanças relacionadas ao parto acabaram por caracterizá-lo como evento médico, cujos significados científicos sobrepujavam outros aspectos. ${ }^{2} 0$ processo parturitivo, então, perdeu seu caráter privativo, íntimo e feminino, sendo projetado para a esfera pública, circunscrevendo-se num contexto onde estão presentes outros atores sociais, com destaque para a figura masculina.

Na década de 40 do século XX, o parto foi institucionalizado no Brasil. Este modelo de atenção priorizou as peculiaridades biológicas da saúde feminina, em detrimento dos aspectos psicossociais. Desta forma, tem-se a fragmentação do corpo da mulher, valorizando-se tão somente a sua capacidade reprodutora, ao invés de percebê-la holisticamente, pretendendo contemplar suas necessidades e anseios como um todo. ${ }^{3}$

Se por um lado a hospitalização foi responsável, em grande parte, pela queda da mortalidade materna e neonatal, por outro, ela resultou na medicalização e controle do período gravídico e puerperal, transformando a mulher em objeto da parturição e em coadjuvante deste momento. O parto deixou, então, de ser um "assunto de mulheres", projetando-se para a ambiência hospitalar e sendo gerido por homens. Pensar em parir associou-se, intrinsecamente, à vivência da dor em sua expressão máxima, cuja significação não era expansiva aos novos protagonistas deste momento, sendo insuficiente para despertar nel es compaixão e ações humanizadas. ${ }^{2}$

Sendo assim, o Ministério da Saúde constatou que a falta de percepção dos direitos femininos e de aspectos fundamentais da humanização do cuidado conduziam a uma assistência desqualificada, julgando imprescindível a proposta de mudanças no modelo assistencial. Com base nesta comprovação, foi criado, através da portaria/GM no. 569, em 1 으 de junho de 2000, o Programa de Humanização do Pré-Natal e Nascimento (PHPN), objetivando, entre outros, garantir consultas de pré-natal, qualidade de 


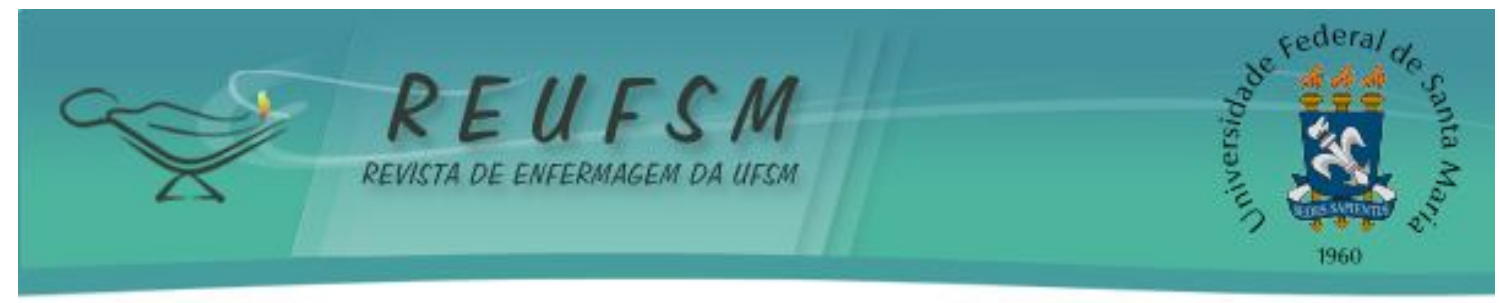

atendimento no parto, assistência organizada, vinculando pré-natal ao parto e puerpério, ampliando, deste feito, 0 acesso das mulheres. ${ }^{1,4-5}$

O PHPN foi estruturado nos princípios da humanização obstétrica e neonatal com condição primeira para o adequado acompanhamento do parto e do puerpério e instituiu uma série de medidas que primam pela melhoria da qualidade da assistência. Entretanto, apesar de ser preceituado pela humanização, a implementação do PHPN não garantiu a prática de uma atenção humanizada em todo o cenário obstétrico, pois ao observar o campo hospitalar obstétrico no Brasil é possível perceber diferentes realidades assistenciais. ${ }^{6}$

Estas realidades assistenciais podem ser encontradas em instituições hospitalares distintas ou podem coexistir numa mesma instituição, na medida em que muitos profissionais aderem ao cuidado medicalizado e fazem uso frequente de intervenções no parto, enquanto outros incorporam à sua prática, ações que são inerentes ao modelo humanizado e desmedicalizado de assistência à mulher em processo parturitivo. ${ }^{6}$

As transformações relacionadas aos modelos de assistência ao parto têm sido implantadas lentamente no Brasil e enfrentam resistência do modelo médico intervencionista. Este modelo expõe a parturiente a técnicas arriscadas, violentas e de eficácia duvidosa. ${ }^{7-8}$

Com base nestas reflexões este estudo teve como objeto de investigação 0 relacionamento entre profissionais de saúde e parturientes no centro obstétrico de uma maternidade pública do interior da Bahia. O interesse por este obj eto surgiu durante a vivência profissional no centro obstétrico de uma maternidade pública da cidade de Feira de Santana na Bahia, ao perceber empiricamente que as parturientes ao serem admitidas no centro obstétrico deste hospital, eram afastadas de seus familiares, permanecendo sozinhas nas salas de pré-parto. Os profissionais de saúde não acompanhavam o processo parturitivo, sendo utilizada como justificativa o reduzido número de profissionais da unidade.

Isto posto, questionou-se: como é o relacionamento entre profissionais de saúde e parturientes no centro obstétrico de uma maternidade pública do interior da Bahia? Para tanto, este estudo teve como objetivo analisar o relacionamento entre profissionais de saúde e parturientes no centro obstétrico de uma maternidade pública do interior da Bahia.

\section{MÉTODO}

Estudo de natureza descritiva, exploratória e qualitativa, realizado em uma cidade do estado da Bahia, pelas suas características sócio-econômicas e importância geográfica, sendo o hospital público especializado na atenção à mulher no ciclo gravídico e puerperal desta cidade o campo empírico desta investigação.

Participaram deste estudo treze puérperas, escolhidas mediante os seguintes critérios de inclusão: Puérperas que estiverem internadas no alojamento conjunto para parto vaginal; puérperas com idade superior a dezenove anos; puérperas de parto simples natural em vértice e puérperas com feto nativivo. Foram excluídas as adolescentes, pois na unidade em estudo, estas parturientes têm o direito de um acompanhante, o que poderia interferir nos dados coletados, pois os profissionais de saúde poderiam mudar suas condutas diante deste sujeito.

O fechamento amostral foi definido pela saturação teórica dos dados, a partir da convergência dos achados ao objetivo proposto no estudo

Os dados foram coletados no período de fevereiro a abril de 2010, após a emissão de parecer favorável pelo Comitê de Ética na Pesquisa da Faculdade de Tecnologia e 


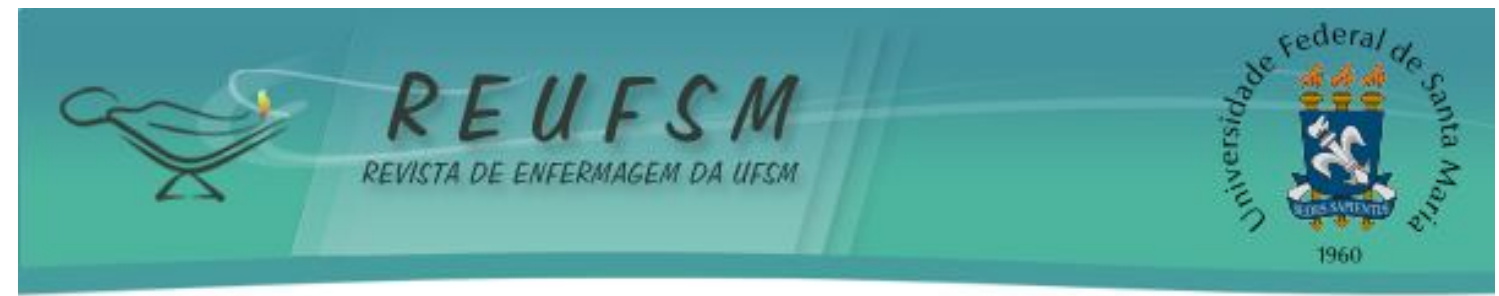

Ciências, campus de Salvador-Bahia, em 14 de setembro de 2009, através do parecer de número 01.382-2009. Todas as participantes assinaram o Termo de Consentimento Livre e Esclarecido.

As puérperas foram identificadas através dos códigos E01 a E13, conforme ordem de realização das entrevistas, respeitando a sua integridade intelectual, social e cultural, conforme a Resolução n. 196/ 96, do Conselho Nacional de Sade.

Para a apreensão do material empírico, foi utilizada a técnica da entrevista na modalidade semiestruturada, e, para auxiliá-la, a realização de desenhos. Os recursos gráficos possibilitaram uma ação interativa entre as entrevistadas e as figuras quando confrontados, sendo possível apreender, dessa forma, como elas se sentiam e vivenciam o processo parturitivo. $^{9}$

A puérpera recebeu uma folha em branco, modelo A4, além de lápis coloridos. Em seguida, foi solicitado que ela realizasse desenhos que representassem a sua vivência durante 0 processo parturitivo. No momento seguinte, realizou-se a entrevista semiestruturada, sendo utilizado um roteiro, com a seguinte questão norteadora: "conte para mim como foi o seu parto". Este momento foi gravado e depois suas respostas foram transcritas na íntegra.

Para a análise dos dados empíricos utilizou-se a Análise de Conteúdo, que corresponde a um conjunto de técnicas de análise das comunicações, que pode expressar uma análise de significados (a análise temática), como também uma análise dos significantes (análise léxica, análise dos procedimentos). ${ }^{10}$

Os desenhos foram submetidos à análise semiológica de imagem, que permitiu buscar uma aproximação científica de qualquer significância em uso nas diversas práticas sociais, prevendo-se a possibilidade de estudar todo projeto significante como um sistema de signos, quaisquer que sejam as diferenças existentes entre a linguagem estudada e 0 modelo de linguagem verbal. ${ }^{11}$

Assim, cada desenho foi submetido ao processo de identificação de símbolos e da decodificação, sendo a seguir os dados desta etapa, relacionados aos da entrevista semiestruturada. Desta maneira foram identificadas as seguintes categorias: o contato inicial com os profissionais de saúde; 0 não reconhecimento da categoria profissional dos trabalhadores do centro obstétrico e estabelecendo relacionamentos no período expulsivo.

\section{RESULTADOS E DISCUSSÃO}

\section{O contato inicial com os trabalhadores da saúde}

A participante abaixo enfatizou em seu depoimento que o tratamento recebido durante o preenchimento de sua ficha na portaria foi descortês indo de encontro ao conceito de acolhimento.

Da médica e das enfermeiras eu gostei, só não gostei muito da pessoa que fez a ficha, pois ela foi um pouco grossa. (E9)

A parturiente esperava encontrar, nas unidades obstétricas, pessoal qualificado para escutá-la e que atendesse às suas demandas com prontidão. Entretanto, por entrar em contato com profissionais que não possuíam estas habilidades, a mulher considerou a atenção recebida como desqualificada.

O Ministério da Saúde ressalta que a anestesia da escuta e a indiferença diante do outro em relação as suas necessidades promovem a imersão do profissional no isolamento, 


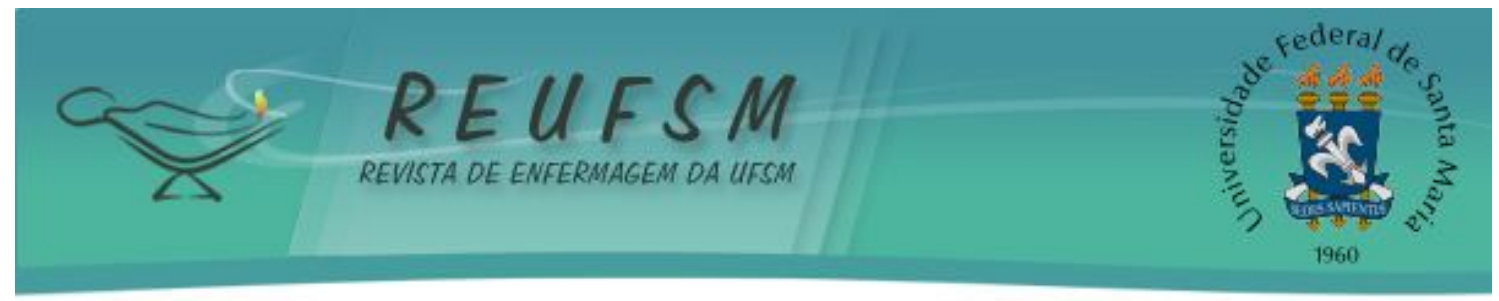

entorpecendo sua sensibilidade e enfraquecendo os laços coletivos através dos quais se constroem a própria humanidade. ${ }^{12}$

Assim, a interação entre $\mathrm{a}(0)$ enfermeira(o) e a parturiente pode ser uma relação de cuidado, na qual o diálogo não é simplesmente uma ação isolada de passagem da informação, mas um ato de cuidar, pois por meio dele pode-se acalmar reduzindo parte do estresse vivenciado durante o processo parturitivo. ${ }^{13}$

Por isso o acolhimento é um aspecto importante e essencial para a humanização o que implica em uma recepção humana e atentiva, na qual as queixas, preocupações, angústias e dúvidas das mulheres são ouvidas e Ihes é garantida a responsabilidade por parte da equipe na resolubilidade dos problemas identificados. ${ }^{14}$

Essa ênfase torna possível a percepção de que a mulher em processo parturitivo cria expectativas em relação ao contato que será estabelecido com os trabalhadores da maternidade, e que a forma como se dará a sua recepção no hospital intensificará ou atenuará os temores em relação à parturição. A recepção e informações corretas, detalhadas, com presteza e afabilidade representam indicadores de acolhimento para as mulheres. ${ }^{15}$

É necessário o acolhimento inicial das parturientes e seus acompanhantes nas unidades obstétricas como uma medida de alívio do desconforto oriundo do processo parturitivo. Por isso os primeiros profissionais que entram em contato com estes atores sociais precisam ser sensibilizados para a participação neste processo.

Conforme relatos das entrevistadas, o relacionamento com os profissionais de saúde foi considerado como um encontro onde predominou a ausência de estabelecimento de vínculos solidários e de coresponsabilidade, o afastamento das necessidades de cada uma das parturientes, além da frieza e impessoalidade.

[...] O médico chegou e falou assim: calma, calma! Com muita ignorância, aí eu falei: ó moço, tenha paciência comigo, não é assim não. (E10)

Eu fiquei chamando eles, falando que já estava na hora, aí a moça veio e disse que pessoas que ficam brigando e gritando na hora de parir só tem que ser tratadas mal, porque já estava sentindo vontade e não ajudava. [...] Os médicos e as enfermeiras sempre ficam falando coisas que me magoaram que eu já sabia como era o parto e que era para eu não parir mais. (E12)

Estes profissionais mostraram-se insensíveis para com a situação vivida pelas parturientes, pois não consideraram a experiência atual como algo novo e sim como uma situação que já deveria fazer parte da vida feminina.

Situação semelhante à vi venciada pelas participantes deste estudo foi encontrada em outra pesquisa, quando concluiu que as mulheres não estavam satisfeitas com 0 atendimento durante o parto, ou na sua decorrente internação, principalmente porque consideravam que alguns profissionais não tratavam bem as parturientes, sendo maleducados e com fala grosseira, al ém de não levarem em consideração as colocações feitas por elas, desconsiderando-as como sujeitos. ${ }^{16}$

O suporte dos profissionais de saúde, durante o processo do parto, configurou-se como confortante para as mulheres. Mostrar-se próximo, preocupado e disposto a cuidar e escutar a parturiente é imprescindível para a criação de laços de confiança e afeição, pois facilitam o processo de parto, transformando-o num momento de cuidado e conforto, levando em consideração sua singularidade na vida de cada família. Há situações em que 


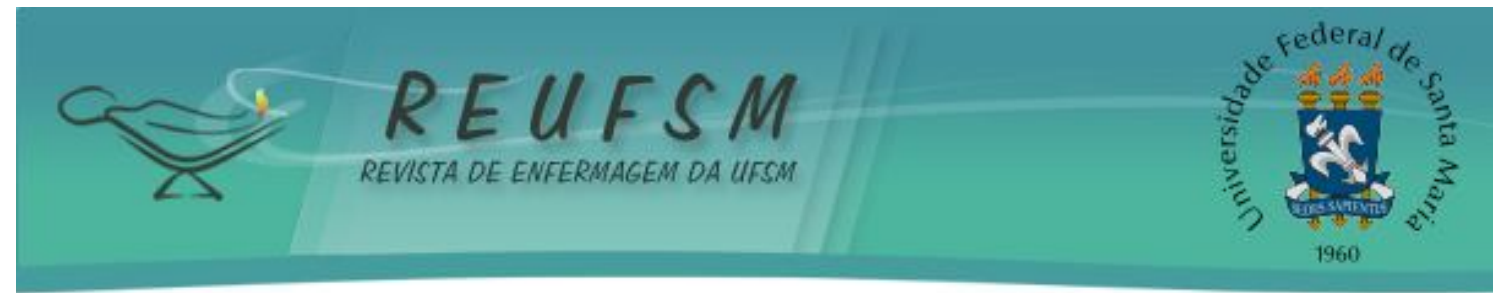

não são necessárias palavras ou ações; basta um olhar que inspire confiança, para confortar. ${ }^{17}$

Nota-se que a insensibilidade e a frieza demonstradas pelos profissionais em discussão foram traduzidas pela entrevistada 13 como desrespeito e agressão. Em seu depoimento a puérpera referiu que não desejava a experiência de um parto nas condições de violação de seus direitos.

[...] nós temos o direito a atenção, a ter respeito, a ser respeitado e não pode passar por determinados constrangimentos, determinadas agressões, porque se você é bem atendido, você é bem tratado, como um ser humano, você tem como evoluir em todos os aspectos, porque acima de tudo nós somos humanos. Até os animais merecem respeito. Não é porque eu ganhei o primeiro que no segundo vão me deixar abandonada, trancar a porta e jogar a chave fora! Não é porque lá está cheio que a gente merece ser pisoteado! Eu não quero passar por isso novamente. (E13)

Isto se deve ao fato de que, situações negativas podem tornar-se traumáticas para as pacientes, influenciando, dentre outros aspectos, a sua percepção no que tange à hospitalização, aos trabalhadores da saúde e ao cuidado. ${ }^{18}$

Um ser humano, ao sentir-se tratado como um "lixo, ou um animal" tem o direito a igualdade, a ser atendido com respeito e dignidade e sua existência como ser humano feridos drasticamente. ${ }^{13}$ Isso leva-nos a refletir que promover uma assistência humanizada é saber ouvir as parturientes e suas necessidades, valorizando sua história de vida, incluindo seus aspectos sociais, psicológicos e emocionais, que podem influenciar de modo significativo sua vivência no parto normal. Para isso, os profissionais de saúde devem acolhê-las, reconhecendo a importância da comunicação em sua prática. ${ }^{19}$

A entrevistada 13 confirmou através do seu desenho a solidão e a dor que enfrentou durante o processo parturitivo. Paralelamente a isso, ela representou a indiferença de uma integrante da equipe de saúde que transitava pelo corredor próximo à sala de parto e não lhe prestou o apoio e a assistência idealizados por ela para aquele momento.

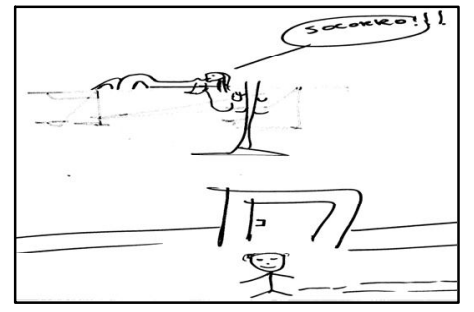

Figura 1 - Ilustração da entrevistada número 13. Negra. Primigesta.

Percebe-se que essa solidão afetou o meio ambiente interno das mulheres. As mulheres, ao permanecerem na sala de pré-parto, sentiram-se sozinhas, muitas vezes esquecidas pelos profissionais, que mesmo sabendo que as mulheres estavam sem acompanhantes não se fizeram próximos, envolvendo-se em outras atividades. Esse 


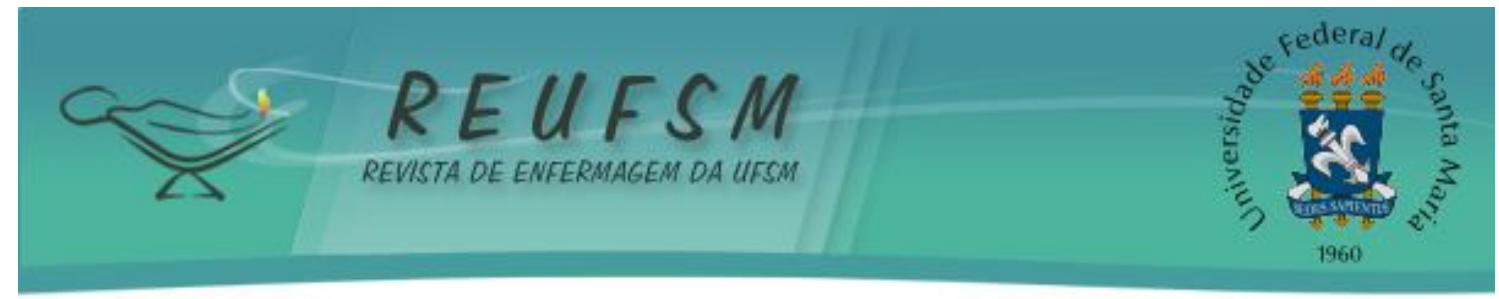

(des)cuidado configurou-se como uma violência silenciosa, indo na contramão do movimento de humanização do parto. ${ }^{20-21}$

O usuário dos serviços de saúde, em geral, não reclama da falta de conhecimento tecnológico no seu atendimento, mas sim da falta de interesse e de responsabilização dos diversos serviços em torno de si e de seu problema. A postura de cuidar dos profissionais de saúde perante os usuários tem muito significado, à medida que eles se sentem valorizados e atendidos em suas necessidades. ${ }^{19}$

Assim os dados empíricos desta categoria representaram uma realidade na qual os profissionais de saúde afastaram-se das parturientes, não sendo estabelecidos vínculos de confiança, solidariedade e coresponsabilidade com as mesmas, sendo estes substituídos por uma relação assimétrica e de poder.

A mulher reage ao que Ihe é oferecido de maneira positiva ou negativa, sendo assim, os sentimentos envolvidos no processo de nascimento são bastante significativos para a parturiente. Quando percebe que os profissionais se mostram sensibilizados com a situação e se solidarizam com as expressões de dor, medo e alegria, a mulher reage com segurança, enxergando a possibilidade de compreensão ao momento que vivencia. ${ }^{22}$

\section{0 não reconhecimento da categoria profissional dos trabalhadores do centro obstétrico}

Outro aspecto percebido nas entrevistas foi o fato de que as entrevistadas não reconheceram a categoria profissional dos componentes da equipe de saúde e das atribuições peculiares a cada um deles durante a parturição.

Eu gostei muito das enfermeiras, elas foram muito atenciosas, alegres [...]. (E5)

Meu parto foi ótimo, foi rápido, gostei do tratamento das enfermeiras, dos médicos. Foi tudo rápido, não fiquei no soro nem levei corte nem ponto. Quando o bebê nasceu tinha enfermeira perto de mim. (E11)

Estas falas podem denotar uma realidade na qual o trabalhador da saúde não se apresenta às parturientes, como uma forma de não ser solicitado durante o processo parturitivo. A apresentação inicial e a presença do trabalhador da saúde é um fator confortante para a parturiente, partindo do princípio de que conhecer alguém na sala de parto será fundamental para a ajuda mútua. ${ }^{17}$

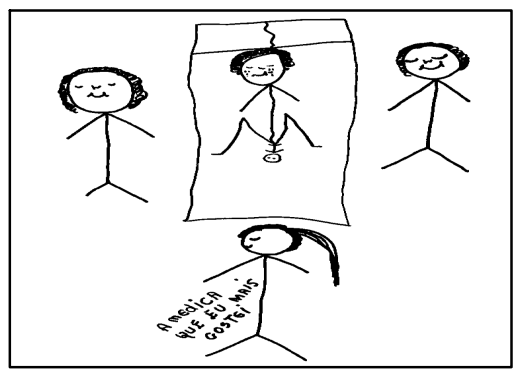

Figura 2 - Ilustração da entrevistada número 7. Negra. Primigesta.

O Ministério da Saúde ${ }^{12}$ determinou que todo usuário do SUS deverá saber quem são os profissionais que cuidam de sua saúde. Todavia, esta disposição não é observada na prática, como se evidencia no desenho da entrevistada número 7. 


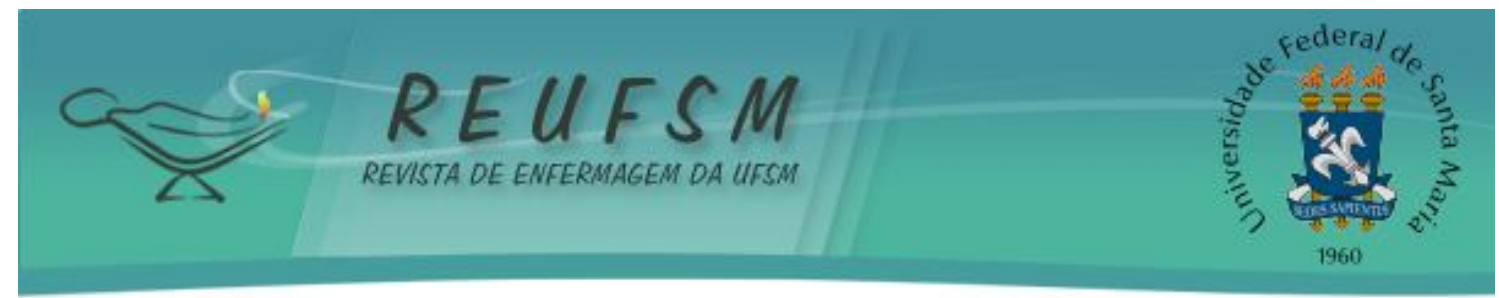

A puérpera não soube identificar os trabalhadores da saúde presentes na sala de parto, uma vez que a equipe de saúde não fomenta a prática de fazer-se conhecer por aqueles que se tornam alvos de seu cuidado. A equipe, na grande maioria das vezes, não se apresenta às clientes, embora seja esta uma etapa indispensável à construção do vínculo e uma das premissas básicas do atendimento humanizado, por isso não há como afirmar que se tratava, de fato, da profissional citada por esta puérpera.

O estabelecimento de uma relação de confiança com os profissionais de saúde fortalece sentimentos positivos que tranquilizam a parturiente. Quando esse relacionamento não é ef etivado, a experiência do parto é af etada de forma negativa. ${ }^{21}$

Confiar e conhecer a função do profissional que lhe presta assistência faz com que a paciente saiba o que esperar do mesmo, depositando nele suas expectativas quanto à sua recuperação. ${ }^{23}$

Assim, considera-se que o contato entre parturiente e trabalhador da saúde e as relações estabelecidas entre esta díade estão aquém do preconizado pelas políticas de humanização do parto e nascimento distanciando-se da idealização das mulheres acerca do tratamento que gostariam de receber na maternidade quando da vigência do nascimento de seu filho. Foi possível observar nos depoimentos das participantes que as ações dos profissionais presentes no cenário do parto, na maioria das vezes, fragmentaram a atenção à mulher e subestimaram o contexto no qual ela estava inserida.

Para acolher e cuidar do ser humano é preciso que ele seja compreendido como um ser singular, autônomo e multidimensional. Para isso, é preciso possibilitar reflexões sobre a necessidade de adotar novas posturas e procedimentos éticos diante da complexidade do ser, a fim de estabelecer a efetiva interação profissional-usuário nas relações de cuidado em saúde. ${ }^{24}$

\section{Estabelecendo relacionamentos no período expulsivo}

O processo parturitivo fragiliza a mulher, colocando-a em situação de vulnerabilidade emocional, fato que intensifica a necessidade de companheirismo, atenção e afetividade. Por ser uma situação caracterizada pela imprevisibilidade, o que pode gerar insegurança e medo, a companhia representa 0 apoio que a mulher necessita para enfrentar essa situação. ${ }^{15}$

Entretanto, diante de um sistema que foi marcado por práticas meramente tecnicistas, distanciadas do calor humano e do afeto, a simples presença de algum trabalhador da saúde na sala de parto, mesmo que esta tenha ocorrido apenas no período expulsivo, conferiu às entrevistadas a idéia de que foram bem atendidas.

0 tratamento da equipe foi ótimo porque logo quando eu comecei a sentir as dores o médico foi logo vendo, pedindo para fazer os procedimentos. Quando a criança sai é ótimo, é a parte melhor. (E1) A equipe me deu muita atenção, apesar de que quando o menino ia sair, a médica mandou segurar o menino, só que eu não agüentava mais, aí eu "despej ei" logo e falei que não ia segurar mais nada. (E2)

Ainda que o contato com a equipe de saúde ocorra de forma rápida e fria, estas mulheres consideraram importante a presença de algum dos seus componentes na sala de parto, o que ficou evidente na ilustração da entrevistada número 2 ao expressar o olhar de indiferença e frieza que a profissional que a acompanhou the direcionou. Em 


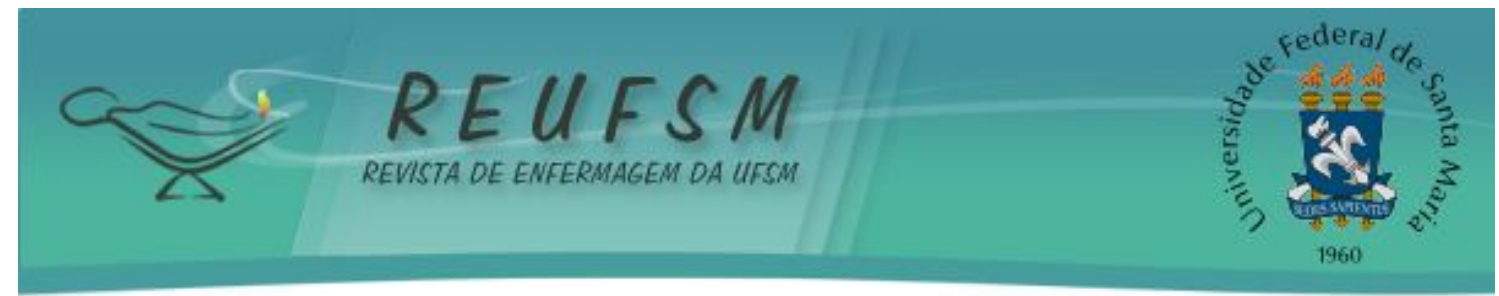

contrapartida, a fisionomia desta parturiente traduziu a felicidade pela presença de alguém ao seu lado no momento do nascimento.

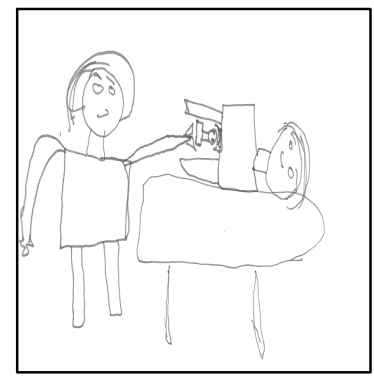

Figura 3 - Ilustração da entrevistada número 2. Negra. Multigesta.

Sendo assim, estes dados empíricos podem significar que as entrevistadas valorizaram a presença dos profissionais de saúde no período expulsivo, devido ao fato de que os mesmos aliviaram a dor do trabalho de parto e do parto através da retirada do concepto, promovida pelas próprias contrações uterinas.

Entretanto, para a entrevistada 4, quando os trabalhadores da saúde estabelecem uma relação de apoio e atenção para com a parturiente e este apoio é percebido desde 0 momento de sua recepção na maternidade até a fase em que se evidencia o parto, tornase possível fazer do processo parturitivo algo prazeroso, facilitando, desta forma, o período o expulsivo.

Foi bem, graças a Deus. Cheguei e fui bem atendida pela médica e pelas enfermeiras. Quando você está num local que é bem atendido, bem recebido, estão ali Ihe apoiando, Ihe incentivando, é mais fácil, você fica mais tranqüila, vai começando a relaxar, aí é gostoso, e quando você vê, já teve. (E4)

A atenção individualizada, pautada por ações que considerem as singularidades que cada momento traz consigo, deveria nortear o exercício dos profissionais que lidam com o momento da parturição. Todavia, o que se observou nos discursos das entrevistadas foram atitudes padronizadas, cujos pilares fundamentaram-se em modelos estigmatizados e reproduzidos na assistência às parturientes, sem, contudo, atentar para as suas especificidades e necessidades.

Teve uma menina que deu muito trabalho do meu lado e a médica ficou meio estressada. A médica ficou nervosa, fechada, eu tentava conversar com ela, ela não respondia nada, ainda disse que eu era 'muito fresca', aí eu falei: 'eu não sou fresca não, senhora, porque a outra está dando trabalho aqui eu vou dar também? (E5)

Confirmando o discurso acerca da insensibilidade da profissional médica que a atendera, E5 expressou no seu desenho a distância que os profissionais mantiveram desta mulher, estando restrita ao leito e em uso de ocitocina endovenosa. Em contrapartida, a parturiente mostrou em seu olhar a expressão de alegria pelo fato de ser acompanhada, ainda que esta assistência se dê sem a formação do vínculo e apenas no momento do expulsivo. 

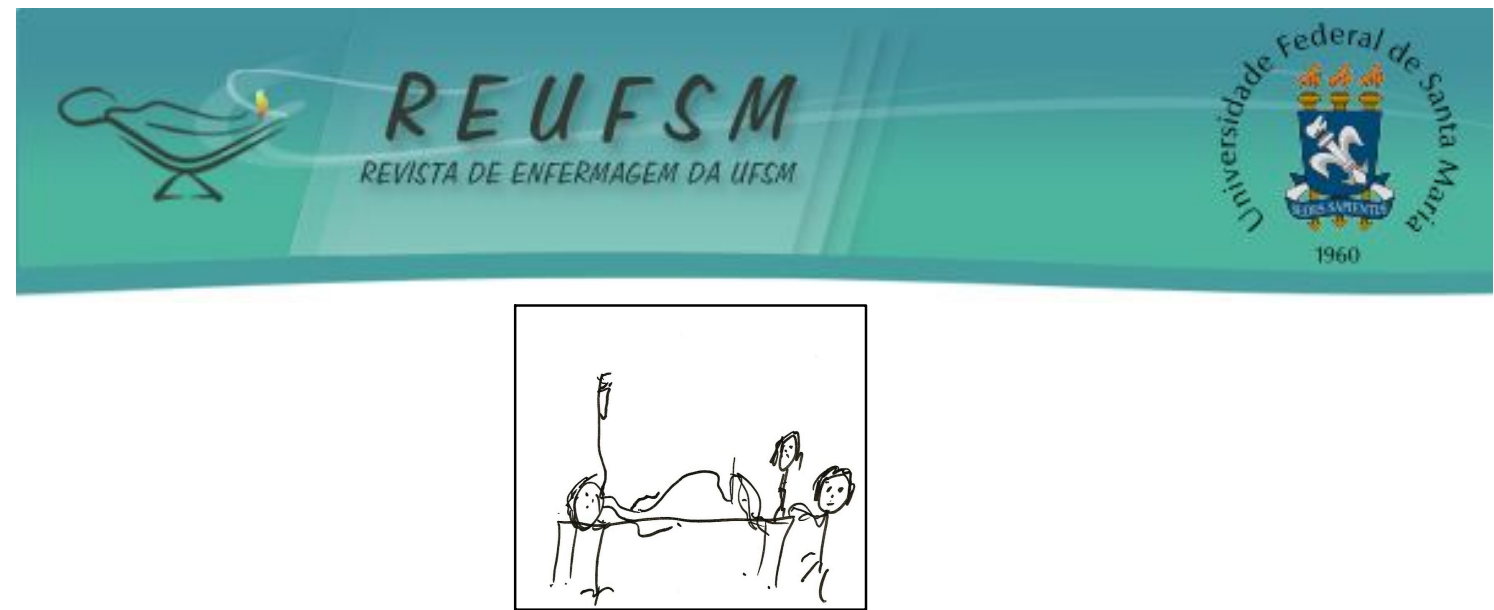

Figura 4 - Ilustração da entrevistada número 5. Parda. Primigesta.

Esta realidade leva a mulher em trabalho de parto a superestimar ações que deveriam ser contínuas no cotidiano do cenário obstétrico, valorizando interações efêmeras pelo simples fato destas terem sido geridas de forma educada.

Meu parto foi bom, eu achei bom porque eu estava achando que ia ser difícil, mas na hora o médico reagiu muito bem. (E3)

Não foi muito bom não, porque eu tive muita dificuldade para ter 0 parto normal, porque é meu primeiro filho, aí eu tive muita dificuldade mesmo para ter, pois a dor foi muito grande, mas valeu a pena. (...) O tratamento do médico que fez meu parto foi ótimo porque ele teve muita paciência comigo. (E6)

A representação a seguir, feita pela entrevistada número 6 fez alusão à sensação dolorosa à qual ela se referiu em sua fala. A cena ilustra a imagem do médico próximo à parturiente, enquanto a equipe de enfermagem encontra-se numa distância maior da mesma, centrando seu cuidado e atenção no recém-nascido. À medida que os profissionais presentes na sala de parto focalizam sua atenção no recém-nascido, percebe-se que a mulher experimenta a solidão e o desamparo.

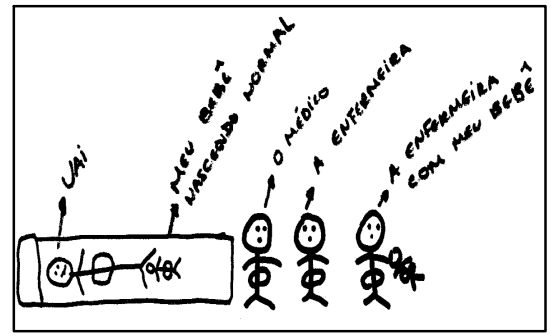

Figura 5 - Ilustração da entrevistada número 6. Parda. Primigesta.

Sendo assim, nota-se que a presença da equipe no período expulsivo pareceu voltada para a atenção às necessidades do recém-nascido, direcionando suas ações para a adaptação deste ser à vida extra-uterina, não valorizando os sinais emitidos pela parturiente, reafirmando a visão da mulher como um sujeito responsável pela reprodução. Por isso, é importante o apoio profissional à parturiente, favorecendo um sentimento de estímulo em relação ao trabalho de parto.

A vivência que a mulher tem da parturição pode ser prazerosa ou traumática, dependendo de sua maturidade e de experiências pessoais ou familiares anteriores, e até daquelas diretamente relacionadas ao sistema de saúde, como a assistência recebida no pré-natal e durante o parto. ${ }^{19}$ 


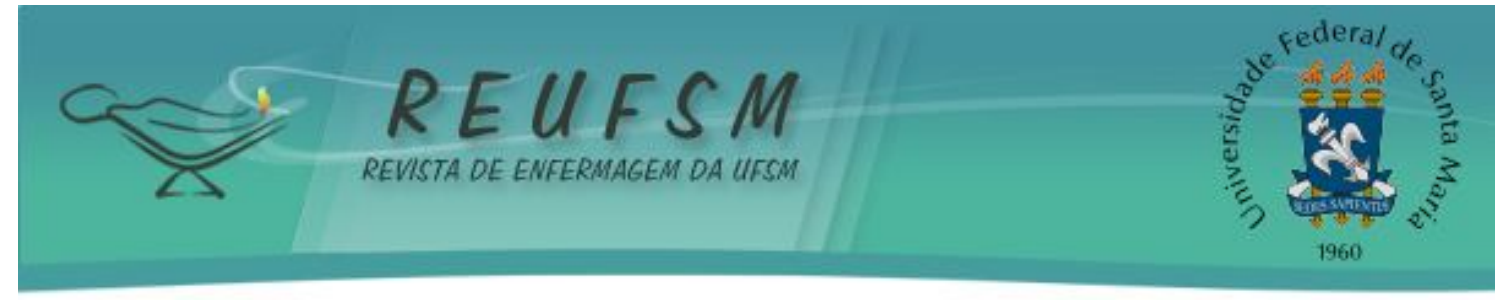

\section{CONSIDERAÇÕES FINAIS}

As experiências descritas e representadas pelos desenhos denotaram a falta de humanização da assistência prestada pela equipe de saúde e a ausência do vínculo. Estas características foram consideradas pelas puérperas como uma assistência fria e indiferente, distante da atenção que elas idealizavam receber na vigência do parto.

A sala de parto foi retratada pela maior parte das entrevistadas como um ambiente de dor intensa, aflição, solidão e abandono. Esta imagem contraria a idéia que se concebe sobre o evento do nascimento, cogitando-se este episódio como um momento de felicidade, realização, celebração da vida.

A atenção humanizada idealizada pelas mulheres e preconizada pelo Ministério da Saúde será factível, apenas, quando os diversos atores envolvidos na parturição se dispuserem a repensar sua prática diária, redimensionando-a, quando necessário se fizer. Isso implicará, inevitavelmente, na reorganização do serviço e no abandono de técnicas padronizadas e atitudes estereotipadas que priorizam a rotina, a tecnologia e a comodidade da equipe em detrimento do bem-estar da mulher.

Sendo assim, haverá a possibilidade de remover a mulher da condição de objeto da parturição, cuja voz não se faz ouvir, devolvendo-lhe a qualidade de protagonista e a capacidade de deliberar sobre questões relacionadas ao seu parto.

Assim, esta pesquisa tem relevância profissional, social e teórica, ao passo que faz emergir aspectos concernentes à assistência prestada pela equipe de saúde durante a parturição, proporcionando, deste modo, o levantamento de indicadores que delineiam esta atenção. Além disso, este estudo poderá contribuir para que a equipe avalie a sua prática e redimensione ações que fomentam uma assistência tecnicista e desvencilhada dos preceitos da humanização. Acredita-se, também, que os dados empíricos poderão estimular a realização de novas investigações.

\section{REFERÊNCIAS}

1. Nagahama EEI, Santiago SM. A institucionalização médica do parto no Brasil. Ciênc saúde coletiva. 2005; 10(3): 652-57.

2. Ministério da Saúde (BR). Secretaria de políticas de Saúde. Área Técnica de Saúde da Mulher. Parto, aborto e puerpério: assistência humanizada à mulher. Brasília: Ministério da Saúde; 2001.

3. Diniz CSG. Humanização da assistência ao parto no Brasil: os muitos sentidos de um movimento. Ciênc saúde coletiva. 2005; 10(3): 627-637

4. Ministério da Saúde (BR). Secretaria de Políticas de Saúde. Área Técnica da Saúde da Mulher. Humanização do Parto: humanização no Pré-Natal e Nascimento. Brasília: Ministério da Saúde; 2000.

5. Boareto MC. Avaliação da política de humanização ao parto e nascimento no município do Rio de Janeiro [dissertação de mestrado]. Rio de Janeiro: Escola Nacional de Saúde Pública, 2003.

6. Vargens OMC, Progianti JM, Silveira ACF. O significado da desmedicalização da assistência ao parto no hospital: análise da concepção de enfermeiras obstétricas. Rev Esc Enferm USP. 2007; 42(2): 339-46. 


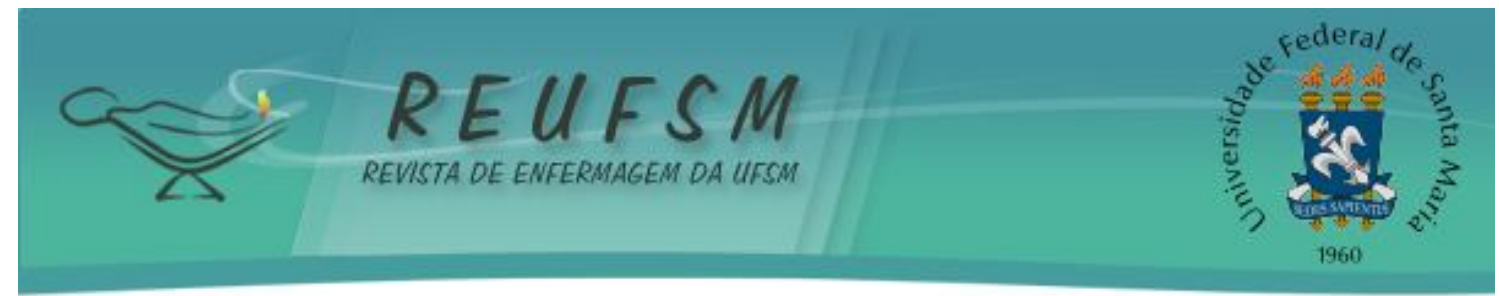

7. Schneck CA, Riesco MLG. Intervenções no parto de mulheres atendidas em um centro de parto normal intra-hospitalar. Ver Min Enf. 2006; 10(3):240-246.

8. Andrezzo HFA. A satisfação da parturiente com seu parto: resultado de três maternidades do sul do Brasil [monografia de graduação]. Florianópolis: Universidade Federal de Santa Catarina ; 2007.

9. Miranda FAN, Furegato ARF, Simpson CA, Azevedo DM. Figuras e significados: recursos gráficos na pesquisa de representações sociais. Rev. Eletr. Enf. [periódico na internet]. 2007 [citado em 12 jan. 2010]; 9(2):526-536. Disponível em: http:/ / www. fen. ufg. br/ revista/ v9/ n2/ v9n2a19. htm

10. Bardin, L. Análise de conteúdo. Lisboa: Edições 70 ; 2007.

11. Bauer MW, Gaskell G. Pesquisa qualitativa com texto, imagem e som. Um manual prático. 7ạ. ed. Rio de J aneiro: Vozes; 2008.

12. Ministério da Saúde (BR). Secretaria de Atenção à Saúde. Núcleo Técnico da Política Nacional de Humanização - Acolhimento nas Práticas de Produção de Saúde. 2a. ed. Brasília: Ministério da Saúde; 2006.

13. Milbrath VM, Amestoy SC, Soares DC, Siqueira HCH. Vivências maternas no processo de parturição. Esc Anna Nery. 2010; 14(2): 462-467.

14. Brandão SMOC. Vivência do acolhimento da mulher encaminhada da Casa de Parto David Capistrano Filho à unidade de referência [dissertação de mestrado]. Rio de J aneiro (RJ ): Universidade Estadual do Rio de J aneiro ; 2008.

15. Armellini CJ, Luz AMH. Acolhimento: a trajetória das mulheres na parturição. Rev Gaúcha Enferm. 2003; 24(3):305-15.

16. Queiroz MVO, Jorge MSB, Marques JF, Cavalcante AM, Moreira KAP. Indicadores da qualidade da assistência ao nascimento baseado na satisfação de puéperas. Texto contexto - enferm. 2007; 16(3):479-87.

17. Frello AT, Carraro TE. Conforto no processo de parto sob a perspectiva das puérperas. Rev Enferm UERJ. 2010; 18(3):441-5.

18. Wolff LR, Waldow VR. Violência consentida: mulheres em trabalho de parto e parto. Saude soc. 2008; 17(3): 138-151.

19. Nascimento NM, Progianti JM, Novoa RI, Oliveira TR, Vargens OMC. Tecnologias utilizadas por enfermeiras durante o parto. Esc Anna Nery. 2010; 14 (3):456-461.

20. Figueirêdo NMA, Tyrrell MAR, Carvalho V, Leite J L. Indicadores de cuidados para o corpo que pro-cria: ações de enfermagem no pré-trans e pós-parto - uma contribuição para a prática de enfermagem obstétrica. Rev Latino-Am Enfermagem. 2004; 12(6): 905-12.

21. Frello AT, Carraro TE. Componentes do cuidado de enfermagem no processo de parto. Rev Eletr Enf. [periódico na internet]. 2010 [citado em 11 jan. 2010];12(4):660-8. Disponível em: http:/ / www. fen.ufg.br/ revista/ v12/ n4/v12n4a10.htm

22. Oliveira ASS, Rodrigues DP, Guedes MVC, Felipe GF. Percepção de mulheres sobre a vivência do trabalho de parto e parto. Rev Rene. 2010; 11(Número Especial): 32-41. 


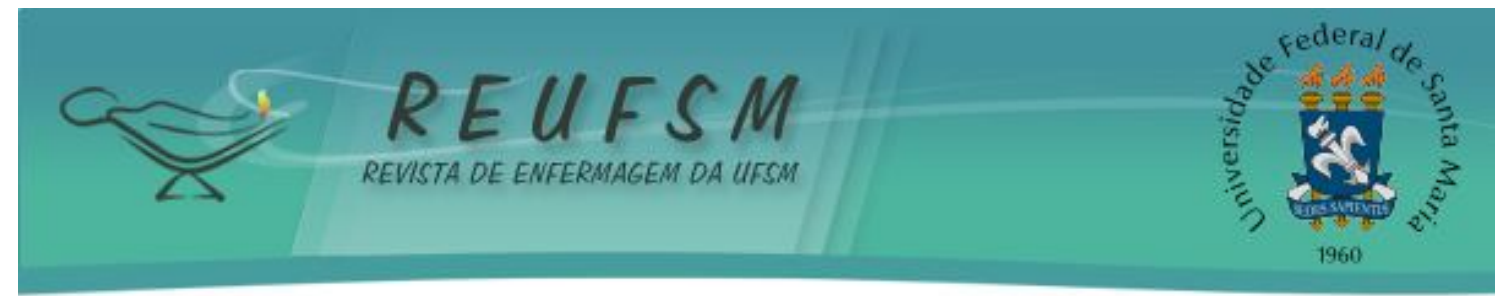

23. Odino NG, Guirardello EB. Satisfação da puérpera com os cuidados de enfermagem recebidos em um alojamento conjunto. Texto contexto - enferm. 2010; 19(4): 682-690.

24. Moreschi C, Siqueira DF, Piexak DR, Freitas PH, Rangel RF, Morisso TS, Backes DS. Interação profissional-usuário: apreensão do ser humano como um ser singular e multidimensional. R. Enferm. UFSM [periódico na internet]. 2011 [citado em 11 mar. 2011];1(1):22-30. Disponível em: http:// cascavel.ufsm. br/ revistas/ oj s2.2.2/ index. php/ reufsm/ article/ view/ 2086/ 1508

Data de recebimento: 23/02/2011

Data de aceite: 06/04/2011

Contato com autor responsável: Luciano Marques dos Santos.

Av. J osé de Sá Maniçoba S/ N, bairro Centro, Petrolina - Pernambuco, Brasil.

CEP 56. 304-917 - Telefone (87)3862-9319/ Fax (87)3862-5013.

E-mail: Iuciano.marques@univasf.edu.br 